Pučko Z., Rebolj D. (2017). “Automated construction progress monitoring using continuous multipoint indoor and outdoor 3D scanning”. In: LC3 2017: Volume I - Proceedings of the Joint Conference on Computing in Construction (JC3), July 4-7, 2017, Heraklion, Greece, pp. 105-112. DOI: https://doi.org/10.24928/JC3-2017/0021.

\title{
AUTOMATED CONSTRUCTION PROGRESS MONITORING USING CONTINUOUS MULTIPOINT INDOOR AND OUTDOOR 3D SCANNING
}

\author{
Zoran Pučko ${ }^{1}$ and Danijel Rebolj ${ }^{2}$
}

\begin{abstract}
In the past few years, a significant progress has been achieved in Automated Construction Progress Monitoring, using a variety of Data Acquisition methods. In this paper, we propose a new method, which shall overcome certain deficiencies recognized in existing methods. The basic principles of our method are, first, to continuously acquire partial As-built point clouds by using multiple helmet-mounted scanners, which scan the indoor and outdoor scenes of locations where work is being done, and record point clouds, locations and time stamps. Second, merging partial, time stamped As-built point clouds to create a complete 4D as-built point cloud of construction in progress. Third, registering elements from the $4 \mathrm{D}$ as-built point cloud by using the existing 3D BIM geometry model as the reference model, and generate the $4 \mathrm{D}$ as-built BIM. The fourth step is the comparison of $4 \mathrm{D}$ as-built BIM and $4 \mathrm{D}$ asdesigned BIM to identify the differences between both models. From the differences in elements, the time schedule deviations are identified and reported.
\end{abstract}

Keywords: automation, construction progress monitoring, data acquisition, 4D point cloud, BIM elements recognition

\section{INTRODUCTION}

In the AECO industry the implementation and application of Building Information Modelling (BIM) technologies is rising in all phases of construction projects. Interoperability standards, mainly the Industry Foundation Classes (IFC) (BuildingSMART, 2016), have matured to the level, where the loss of information through the lifecycle of a building can be avoided completely. The IFC schema is being constantly developed and now includes all important information about the object and the project.

In project management, geometric design data is extended with project plan data, which includes the time and the cost dimension of a building project. Specific software enables to upgrade the 3D BIM (model) into 4D and 5D BIM respectively (Brisk, 2007; Rundell, 2006; Rundell and Stowe, 2007; Tulke and Hanff, 2007; Muhič, 2008). These models are important for optimal Construction and Operation, as they are the basis for efficient monitoring of relevant activities (Pučko et. al, 2015).

In the construction phase, it comes to many deviations from the plan. There are many causes for deviations, like incompetent contractors, inconsistent design, inadequate materials etc., but before we can analyse the causes and adapt the plan, we need up-todate information about the construction progress, especially about the differences between as-designed and as-built states. Progress monitoring is of most importance for optimal project realisation, it is, however, time and cost consuming. It is therefore no surprise that

$1 \quad$ PhD candidate, Faculty of Civil Engineering, Transportation Engineering and Architecture, University of Maribor, Maribor, Slovenia, zoran.pucko@um.si

2 Professor, Faculty of Civil Engineering, Transportation Engineering and Architecture, University of Maribor, Maribor, Slovenia, danijel.rebolj@um.si 
many researchers have focused their effort on automation of construction progress monitoring. (Pătrăucean, V. et al., 2015; Kopsida, M., Brilakis, I. \& Vela, P., 2015; Omar, T. $\&$ Nehdi, M.L., 2016) give a very good overview and comparison of different approaches, results and shortcomings.

In our research, we have focused on methods based on $4 \mathrm{D}$ as-build $(\mathrm{AB})$ vs. $4 \mathrm{D}$ asdesigned (AD) comparison, sometimes also referred to as Scan-vs-BIM. Point cloud based methods using laser scanning, e.g. (Bosché, Ahmed, Turkan, Haas, \& Haas, 2015), are considered expensive and time consuming. Less expensive point cloud reconstructions through images, e.g. (Golparvar-Fard, Peña-Mora, \& Savarese, 2015), still leave open the problem of progress measurement for interior tasks such as tiling, painting etc. According to (Omar \& Nehdi, 2016) laser scanning is still not widely employed due to its high cost, need for a clear line of sight, and the difficulty of using it in congested interior work.

Our goal was to develop a method, which would resolve the reported deficiencies of additional efforts of point cloud generation, and the problem of incomplete point clouds due to obscured building elements, or due to missing parts (e.g. indoor or outdoor scanning only). The basic idea is to continuously generate $4 \mathrm{D}$ point clouds on the go by gathering scans from workers' helmets, equipped with appropriate 3D scanners. The method is further explained in the paper.

\section{Methodology}

Our method for automated construction progress monitoring requires the existence of 3D and 4D AD BIM. The 4D AD BIM is constantly compared to the situation on-site, where a point cloud (4D AB PC) is being merged using partial point clouds continuously generated by scanning devices built into workers' protection helmets.

Since workers are always where work is being done, partial point clouds ensure views on all emerging building components from inside and outside of the building. In cases where activities are performed by automatons, these are equipped with necessary scanning equipment as well. Partial point clouds are enhanced with location and time information, which ensure adequate merging into the total $4 \mathrm{D} \mathrm{AB} \mathrm{PC}$ of a specific time frame.

In the next step, elements from the $3 \mathrm{D}$ AD BIM are used together with the $4 \mathrm{D} \mathrm{AB} \mathrm{PC}$ as the input for the registration process, which gives as the result an object model of the on-site situation, the $4 \mathrm{D} \mathrm{AB} \mathrm{BIM}$. The $4 \mathrm{D}$ AB BIM is then compared to the $4 \mathrm{D}$ AD BIM and a list of differences in elements is generated. Since the difference elements are linked to activities, the delayed activities as well as those ahead of due time are recognised and listed.

We see the novelty of our method in the way of point cloud acquisition, which 1.) is continuous, and 2.) does not require any additional monitoring or surveying activities.

\subsection{Partial point cloud acquisition}

The basic supposition of our method is that work is always being done by or in the presence of workers, or autonomous automata. It is therefore logical to scan and communicate the situation with their help, but in a way, which doesn't hinder them in their primary work. A single data acquisition system, which shall be built into a security helmet, includes a 3D scanner, a positioning subsystem and a subsystem for wireless communication. The proposed method diminishes many deficiencies of related methods, like high cost of high precision scanners and their manipulation, positioning, obstacles, additional work etc. It is anticipated to use low cost equipment from the category of 3D sensing technologies producing Range images or depth images (Omar, T. \& Nehdi, M.L., 
2016). In our experiments, we were using Kinect 2 sensor, but many others would fit this category (e.g. Xtion Pro Live 3D sensor or Structure sensor). Table 1 is showing the comparison of adequate equipment.

Table 1: Comparison of data acquisition devices.

\begin{tabular}{|c|c|c|c|c|c|}
\hline Devices & $\begin{array}{l}\text { Types of } \\
\text { data }\end{array}$ & $\begin{array}{l}\text { Available } \\
\text { environment }\end{array}$ & Sensing range & Portability & Price \\
\hline $\begin{array}{l}\text { Stationary } \\
\text { camera }\end{array}$ & 2D images & $\begin{array}{l}\text { Both indoor and } \\
\text { outdoor }\end{array}$ & Long & No & $>500 \$$ \\
\hline Potable camera & 2D images & $\begin{array}{l}\text { Both indoor and } \\
\text { outdoor }\end{array}$ & Long & Yes & $>500 \$$ \\
\hline Flash LADAR & 3D images & Indoor & $\begin{array}{l}\text { Short (less than } 10 \\
\text { m) }\end{array}$ & Yes & $>500 \$$ \\
\hline $\begin{array}{l}\text { Stereo vision } \\
\text { camera }\end{array}$ & $\begin{array}{l}2 \mathrm{D}+3 \mathrm{D} \\
\text { images }\end{array}$ & $\begin{array}{l}\text { Both indoor and } \\
\text { outdoor }\end{array}$ & $\begin{array}{l}\text { Long (accurate } \\
\text { less than } 10 \mathrm{~m} \text { ) }\end{array}$ & Yes & $>1500 \$$ \\
\hline RGB-D sensor & 3D images & $\begin{array}{l}\text { Both indoor and } \\
\text { outdoor }\end{array}$ & $\begin{array}{l}\text { Short (less than } 5 \\
\text { m) }\end{array}$ & Yes & $<200 \$$ \\
\hline $\begin{array}{l}\text { Drone with } \\
\text { camera }\end{array}$ & $\begin{array}{l}\text { 2D images + } \\
\text { GPS }\end{array}$ & Outdoor & Long & Yes & $>1500 \$$ \\
\hline
\end{tabular}

The helmet scanning system has to fulfil the following requirements:

- indoor and outdoor operation

- point cloud acquisition in a worker's proximity (up to $3 \mathrm{~m}$ )

- location and time perception

- power autonomy for a working day (batteries, wireless powering, etc.)

- full mobility

- continuous point cloud acquisition and local cleaning

- wireless communication with the server

- acceptably low cost

Although the anticipated scanning technology does not ensure high point cloud accuracy and density, it does fit the required criteria and enables efficient element registration and identification, as shown in section 2.3. The Helmet scanning system is sending partial point clouds to the server in either specific time intervals or when the local memory is full. Figure 1 is illustrating a scenario of partial point cloud acquisition in the working activity vicinity using helmet integrated scanning equipment.

\subsection{Partial point cloud merging}

Partial point clouds are accompanied with information on a referential location and time of acquisition. Both information is used in the process of merging partial point clouds into the total point cloud, representing the on-site situation at a specific time. Although the partial point clouds are gathered in a time interval (level of magnitude of an hour), they depict the situation at the end of the time interval, since elements observed earlier could not change unobserved in the meantime.

Merging is done using adequate software on the server. A $4 \mathrm{D} \mathrm{AB} \mathrm{PC} \mathrm{is} \mathrm{generated,}$ which includes all elements that have been built in a specific time frame (an illustration of a $4 \mathrm{D} A B \mathrm{PC}$ is shown on Figure 2). This means the $4 \mathrm{D}$ AB PC is not necessarily complete 
since elements built before the time frame might not have been observed and could be missing. However, the operation of completing the $4 \mathrm{D}$ model is done in the following step, as it is easier to merge elements on the object model than on the point cloud level.

Research related to point cloud merging is in still progress. It shall solve the problems of exact positioning of partial point clouds in a common coordinate space, as well as point cloud cleaning. In our experiment, CludCompare has been used for manual partial point cloud merging.

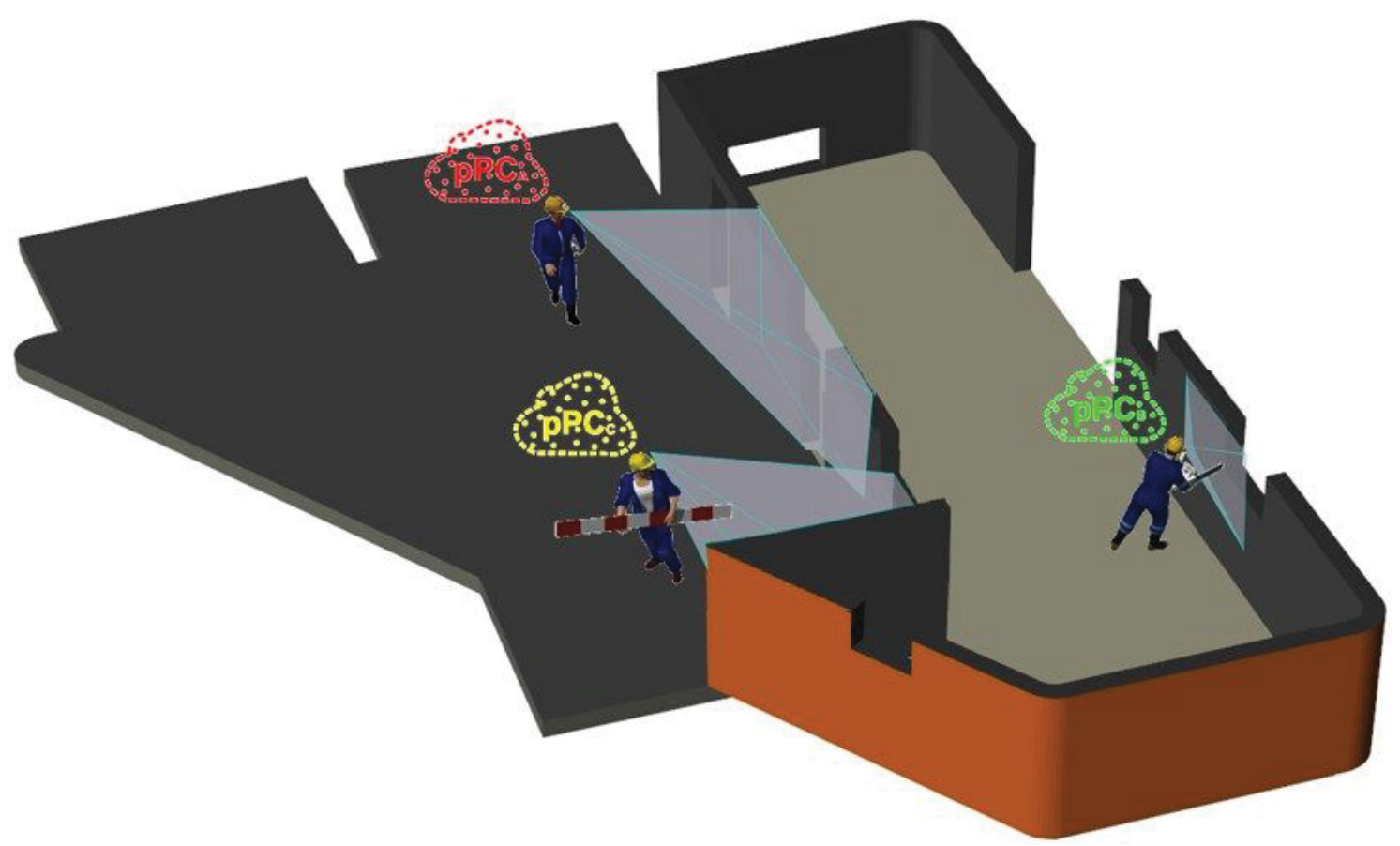

Figure 1: Scenario of indoor and outdoor on-site partial point cloud acquisition using multiple helmet-mounted scanners

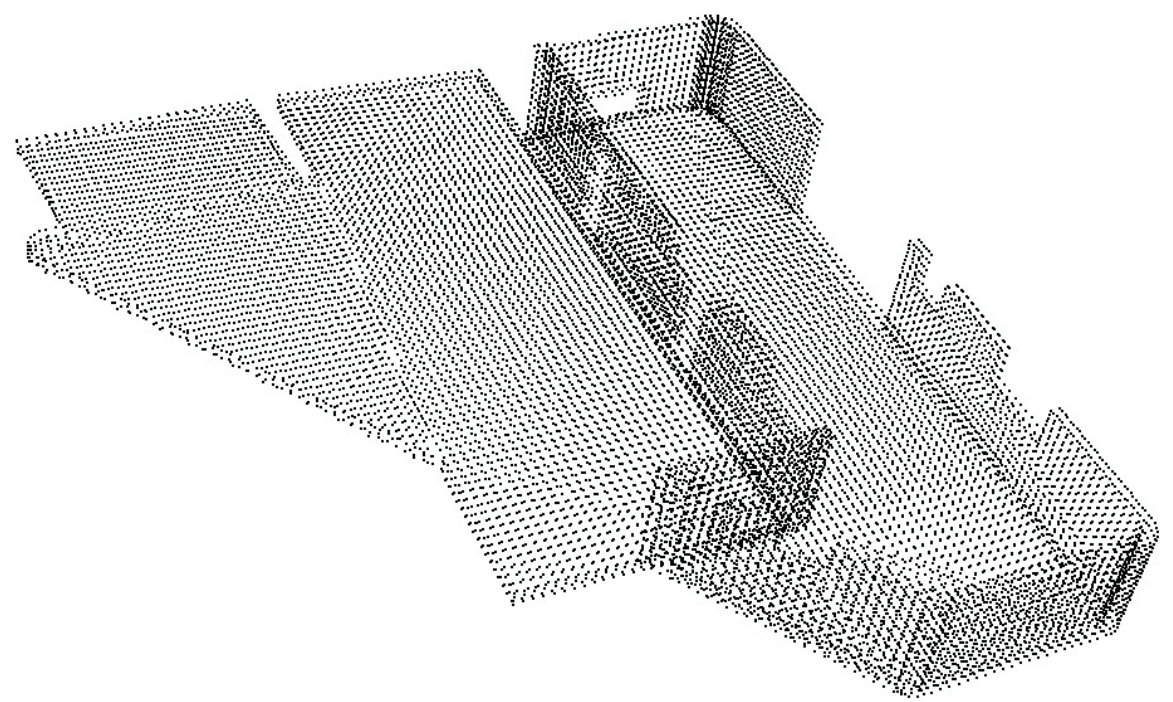

Figure 2: 4D as-built point cloud (4D AB PC) of the observed building after merging partial point clouds. 


\subsection{Generating $4 \mathrm{D}$ AB BIM by registration of 3D BIM elements contained within $4 \mathrm{D} A B$ PC}

3D BIM includes the exact geometry of each building element. In this step of our method, we use the merged $4 \mathrm{D} \mathrm{AB} \mathrm{PC}$ and the $3 \mathrm{D}$ BIM to register all elements of the 3D BIM contained in the $4 \mathrm{D}$ AB PC. For registration, we used in-house software, which recognises elements correctly, when cloud points cover half of their surface. The result is a $4 \mathrm{D} A B$ BIM, which contains all elements found in the observed time frame. This means some elements that already exist on-site could be missing, therefore the new $4 \mathrm{D} \mathrm{AB} \mathrm{BIM} \mathrm{is}$ merged with the previous version of it. Figure 3 is showing an example of the recognition process.
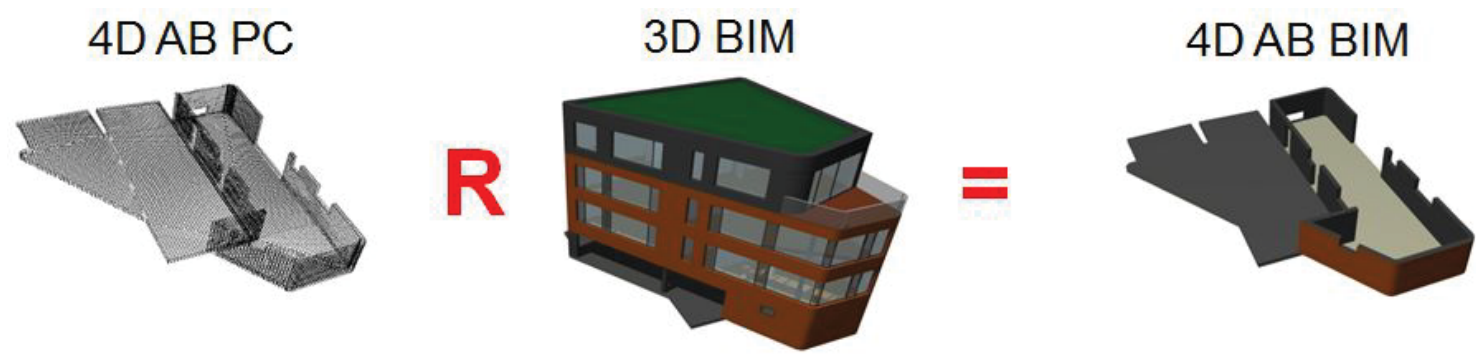

Figure 3: Registration using $4 \mathrm{D} \mathrm{AB} \mathrm{PC}$ and $3 \mathrm{D}$ BIM to generate 4D AB BIM.

\subsection{D AB BIM and 4D AD BIM comparison}

$4 \mathrm{D} \mathrm{AB}$ BIM is representing all elements of the construction projects that have already been built up to the specific point in time. Since we have supposed the existence of a 4D AD $\mathrm{BIM}$, we can find the deviations from the plan by a simple difference set operation on $4 \mathrm{D}$ $\mathrm{AD}$ and $4 \mathrm{D} \mathrm{AB} \mathrm{BIM}$. The difference is represented as a list of elements that either are built ahead of the planned time or have not been built on time. Since each element is linked to an activity in the project schedule, deviations in the schedule can be identified and listed. Figure 4 is illustrating the difference operation on an example.
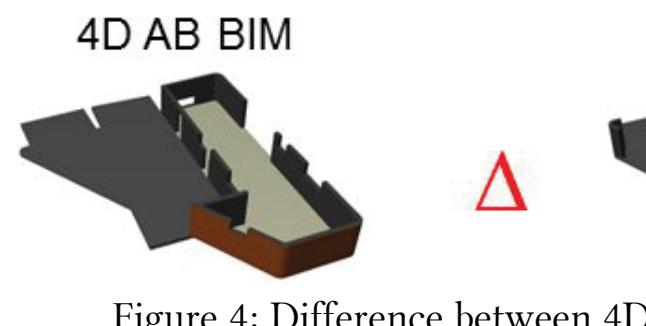

Figure 4: Difference between 4D A
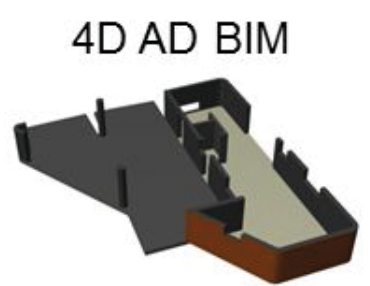

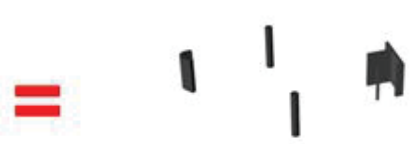

\section{diferences}

From the example, we can see that the missing elements should have been built at the specific point in time. These elements are emphasized on Figure 5, which is showing them in the context of the 4D AD BIM. Figure 6 is showing the project schedule and the consequence of the missing elements, which represents a delay. 


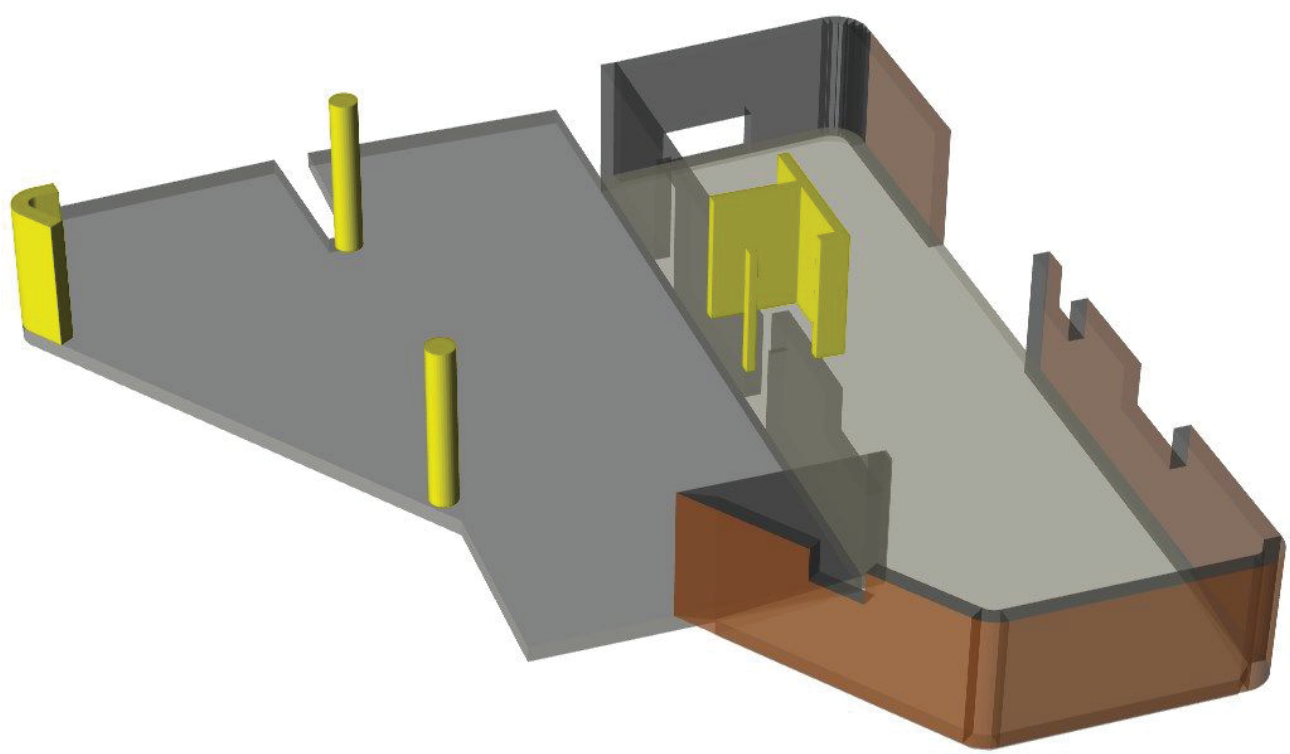

Figure 5: Differences between both models (difference objects - 4D AD BIM with missing elements emphasized).

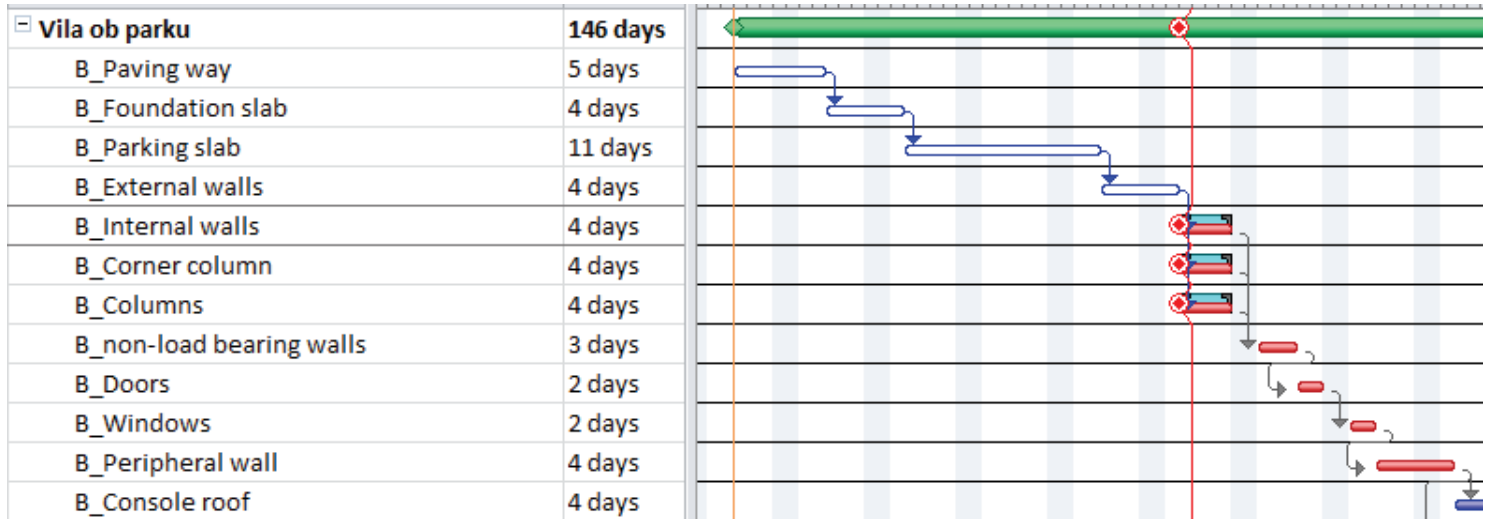

Figure 6: Differences in time schedule (difference activities).

\section{CONCLUSION}

The paper is presenting a new method for the acquisition of point clouds of buildings under construction, with the purpose of enabling continuous automated construction progress monitoring. The main advantages of the method in comparison with existing scan-vs-BIM methods are: continuous monitoring of all activities and hence the real time detection of the built elements, which enables early detection of deviations in the schedule plan, and no additional time and cost consuming monitoring activities.

There are also some limitations: communication infrastructure and the server have to be set-up and maintained, and all protective helmets have to be upgraded with scanning add-ons, which have to be maintained constantly. However, a Wi-Fi network is being installed on many building sites for other purposes already, and the IT staff already has to maintain various servers. We have also anticipated helmet equipment in an affordable price range.

Our project is not finished yet and there still exist some open problems, which are mainly related to the acquisition and merging of partial point clouds. In our experiment, we have adjusted the locations of partial point clouds manually, but for the system to 
operate autonomously the helmet locations have to be determined automatically. We have anticipated several solutions, ranging from inertial positioning using several fixed beacons for location adjustment, Wi-Fi based positioning, and some others. Our advantage is that we can improve an approximate location with the help of some significant elements, which we could recognise from the BIM. Therefore, we will only need a rough location from the positioning system. The existence of the 3D AD BIM is also significant for the merging of partial point clouds.

After solving the mentioned open problems, we plan to move from the testbed to a real construction project, where we plan to use (probably awkward) prototype scanning helmets, communication network and a server for partial point cloud merging, registration and comparison of $4 \mathrm{D} \mathrm{AD}$ and $4 \mathrm{D} \mathrm{AB} \mathrm{BIM}$.

\section{ACKNOWLEDGEMENT}

This research was supported by the company HERMES d.o.o. through Agreement for Cofinancing of Research Work No. 10-2017-ZP-DDP / 1-2017-RD-PZ and by the company PILON AEC d.o.o. through Agreement for Co-financing of Research Work No. 08-2017ZP-DDP. Authors wish to thank for their valuable support and cooperation.

\section{REFERENCES}

Brisk S. (2007), Building Information Modeling in Practice, White Paper, Autodesk, available at: http://revitmep.blogspot.com/2007/10/building-information-modelingin.html [24.06.2013].

Buildingsmart, 2016, available at: http://www.buildingsmart-tech.org/ [03.10.2016].

CAD Addict (2013), List of BIM Software \& Providers, available at: http://www.cadaddict.com/2010/03/list-of-bim-software-providers.html [24.09.2016].

Eastman C., Teicholz P., Sacks R., Liston K., BIM Handbook: A Guide to Building Information Modeling for Owners, Managers, Designers, Engineers, and Contractors, $2^{\text {nd }}$ Edition, New Jersey: Wiley Publishing, 2011.

Kopsida, M., Brilakis, I. \& Vela, P., 2015. A Review of Automated Construction Progress and Inspection Methods. Proceedings of the $32^{\text {nd }} C I B$ W78 Conference on Construction IT, (January), pp.421-431.

NBS National BIM Report 2014, available at: https://www.thenbs.com/knowledge/bimlevels-explained [04.10.2016].

Omar, T. \& Nehdi, M.L., 2016. Data acquisition technologies for construction progress tracking. Automation in Construction, 70, 143-155.

Pătrăucean, V. et al., 2015. State of research in automatic as-built modelling. Advanced Engineering Informatics, 29(2), pp.162-171.

PUČKO, Z., ŠTRUKELJ, A., ŠUMAN, N. (2015), Project management software based on BIM to evaluate construction time and cost. Conference proceedings, 12th International Conference Organization, Technology and Management in Construction, 02-05 September, 2015.

Rundell, R. (2006), BIM and Cost Estimating, Cadalyst, available at: http://www.cadalyst.com/cad/building-design/1-2-3-revit-bim-and-cost-estimatingpart-1-3350 [24.06.2013].

Rundell, R., Stowe, H. K. (2007), 1-2-3 Revit: BIM and Project Planning, Cadalyst, available at: http://aec.cadalyst.com/aec/article/articleDetail.jsp?id=408794 [24.06.2013]. 
Automated Construction Progress Monitoring Using Continuous Multipoint Indoor and Outdoor 3D Scanning

Tulke, J., Hanff, J. (2007), 4D Construction Sequence Planning - New Process and Data Model, available at: http://www.inpro-project.eu/media/4d_jantulke.pdf [24.06.2013]. 